growing, grown-diffusion, melt-back diffusion, and double-diffusion. Dr. Kendall also made an objective comparison of silicon and germanium transistors, stressing the advantages of the former in hightemperature applications.

In $\mathrm{a}_{\mathrm{e}}$ conference where one often heard of the need for semiconductor materials of high quality, it was interesting to hear of some of the chemist's difficulties in Mr. J. M. Wilson's (Standard Telephone Laboratories) paper on "The Preparation of Very High Purity Silicon". The high segregation coefficient of boron makes it very difficult to purify by means of the zone-refining technique, which has been used so successfully with germanium. After reviewing a number of methods, Mr. Wilson described his work on a process which starts with the thermal decomposition of silane $\left(\mathrm{SiH}_{4}\right)$. The silicon can be produced in a crystalline form without having to use crucibles; this feature is attractive in view of the high reactivity of silicon with the crucible materials.

Dr. A. F. Gibson (Royal Radar Establishment) dealt with "Avalanche Injection" and the possibility of utilizing it in certain devices. When the field across a filament of $n$-type germanium exceeds a critical value, avalanche multiplication gives rise to a rapid inerease in conductivity; as a result, the voltage-current characteristic exhibits a negative resistance region, similar to that obtained with a gas discharge tube. In order to limit the current, and hence the dissipation, in the high-current condition, the area of one of the contacts to the germanium is made small. Dr. Gibson then discussed a device, having two $n+$ contacts and one $p+$ contact to the germanium, which is analogous to the thyratron, and in which the current flowing into the $p+$ contact controls the voltage-current characteristic at the other two.

Dr. D. F. Taylor (Ferranti), in a paper on "Improved Junction Fabrication", dealt mainly with the problems of making alloyed junctions in silicon. $\mathrm{He}$ considered the conditions that are necessary for regrowth to take place. $\mathrm{He}$ showed that, when alloying an aluminium wire to a silicon wafer, if, during the cooling cycle, the wire is maintained at a higher temperature than the molten region no regrowth takes place; Dr. Taylor suggested that the reason why good diode characteristics are obtained under these conditions is that diffusion takes place at the alloy/silicon interface during the alloying. Finally, he considered some aspects of the 'limited' type of alloy process, such as takes place when a small 'dot' is alloyed to a silicon wafer.

The last paper in the conference was given by $\mathrm{Dr}$. M. Smollett (Mullard), whose subject was "Germanium Photo-transistors". After considering the creation of hole-electron pairs in germanium when light shines on it, he described the photo-electric properties, including the spectral response, of a $p-n$ junction diode in which the $p$-region is made very thin. He then analysed the operation of the phototransistor, which differs from the diode in that it can produce substantial multiplication of the current that is produced by the holo-electron pairs that are generated by the incident light. Possibly their main disadvantage is the fact that hole-electron pairs produced by thermal agitation also contribute to the output current; Dr. Smollett indicated ways of minimizing this.

Each paper was followed by a discussion, during which many useful and stimulating comments were made.

\section{HERRING IN THE NORTH SEA}

$I^{N}$

1955 the East Anglian herring fishery failed. This is a drift-net fishery which exploits different populations during October and November, and its success is to a large extent dependent on the dates of the full moons which, though not propitious for the 1955 season, could not possibly provide the complete reason for the failure. However, several changes had taken place since the Second World War. In 1948 the Danes started trawling for young immature herring and they were followed by the Germans, Dutch and French. These 'industrial' herrings were used for processing into fish meal. While the catches were at first insignificant they increased enormously during the following seven years until the number of herrings trawled far outnumbered those caught during the East Anglian fishery. Another rapid development since 1951 was the trawl fishery for adult herring in the Channel and North Sea Southern Bight by German, French, Duteh, Belgian, Polish and Icelandic fishermen. The landings from this new fishery have led to what might appear to be a shift from the fish being landed by drifters to being landed by trawlers. Coincident with these changes in the fisheries there have been changes in the environment (for example, the amount of food (Calanus) available) and in the biological characters of the herrings (as, for example, the mean length at various ages and, apparently, age at first maturity).

In a recent fishery investigation, published under the title "On the Herring of the Southern North Sea"*, Dr. D. H. Cushing and Mr. A. C. Burd have attempted to sort out these complexities, about which fishery biologists and fishermen have strong and divided views.

Their paper consists of four parts, the first of which, by Dr. Cushing, is concerned with the homogeneity and character of the Southern Bight stocks. In the second part he considers the natural changes that have occurred in the populations, changes among others, in age distribution, length, nature of recruitment, in the environment and in the fishery. Part 3, by Mr. Burd, discusses the changes that can be ascribed to fishing, while in the last section Dr. Cushing considers the effect of fishing on the stock. It is impossible in a review of this length to discuss their evidence in detail, but it leads them to believe that, through the advance in maturity, the fish are caught sooner in their life and this reduces the older age-groups which, together with the southern North Sea and Channel trawl fishery, reduces the November East Anglian catches of older fish. The danger caused by 'industrial' fishing of immature herrings receives a verdict of 'not-proven'. These conclusions should be put in perspective by pointing out that Dr. W. C. Hodgson, and many of the fishermen themselves, believe that this 'industrial' fishing to the north provides at least part of the explanation of the failure, and probably a large part.

Perhaps the wisest words in this paper are in Mr. Michael Graham's preface: "Dogmatism is out of place in this subject, ... and in addition, data on highly migratory fisheries are always difficult to interpret".

T. B. BAGENAL

* Ministry of Agriculture, Fisheries and Food. Fishery Investigations. Series 2, Vol. 20, No. 11: On the Herring of the Southern North Sea. By D. H. Cushing and $A$. C. Burd. Pp. iv +31 . (London: H.M. Stationery Office, 1957.) 8s. $6 d$. net. 